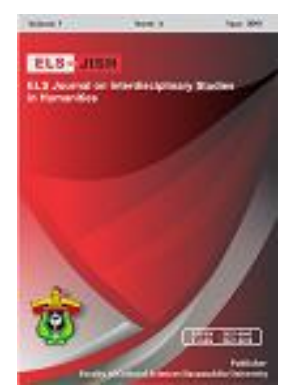

ELS-JISH

ELS Journal on Interdisciplinary Studies on Humanities

Volume 2 Issue 2, 2019

ISSN (print) : 2621-0843

ISSN (online) : 2621-0835

Homepage : http://journal.unhas.ac.id/index.php/jish

\title{
Retrieval-Practice for Enhancing Students' Memory in Learning Vocabulary of Preschool Period
}

\author{
Risa Mufliharsi ${ }^{1}$ \\ ${ }^{1}$ risa.mufliharsi@unindra.ac.id
}

\begin{abstract}
The purpose of the research is applying retrieval practice for enhancing students' memory in learning vocabulary of preschool period. The data is collected by the data from PAUD Sakura Swadiri in Jakarta in 2017/2018 academic year in four times from 20 students. The instrument that used is direct vocabulary pretest and post test oraly. It is used to find out the progress of each students. The ages of students started from 3 up to 5 years old. The result showed that retrieval practice is effective for enhancing students' memory in learning vocabulary of preschool period. In this case, retrieval practice improve students memories.
\end{abstract}

Keywords: Retrieval Practice, Students' Memory, Learning Vocabulary, Preschool

How to cite: Mufliharsi, R. (2019). Retrieval-Practice for Enhancing Students' Memory in Learning Vocabulary of Preschool Period. ELS Journal on Interdisciplinary Studies in Humanities, 2 (2), 313 320

\section{Introduction}

Memory has cognitive function involving brain in getting information especially in learning language. Memory works as an input the data of language, then if we need the data which has input to our memory, we just recall it, and process it. that's why naturally memory has big capasity to store all of input. Unfortunately, in processing, not all of memory can fill the room in the brain. So that, this condition makes someone sometimes difficult to remember related for his experience for example.

The efficiency of human memory recall is astounding. Most of what we remember is by direct retrieval, where items of information are linked directly a question or cue, rather than by the kind of sequential scan a computer might use which would require a systematic search through the entire contents of memory until a match is found. It indicates that memory has many kinds of memory. They are experience memory, conceptual memory, and word memory. Experience memory relates to past events of someone did. If the events mean for the someone, he will keep the memory in long term memory. Then, conceptual memory relates 
construction which built by many facts happened. The last, word memory is a memory that connect the concept with sounds of it. If someone forgets the word, it means that he fails to keep in long term memory. It can be assume that the concept only in short term memory which get temporary information. If there is no reduplication, the information will get lost.

According to this situation, it is important for the language teacher to enhancing the language that has been learned. One of the data in language is vocabulary which related to words that has been learned. In this case, one of ways to maximize our memory by retrieval practicing, including learning English which as English as Foreign language (EFL) in Indonesia.

Vocabulary is one of fundamental aspect in learning language, included foreign language because it can be the first input that someone recognition. Moreover, learning English vocabulary has integrated process which fills the the skills that imply the measurement of English itself. For example: Oral vocabulary is an essential oral language component, playing a significant role in children's conceptual knowledge development and building background knowledge to support the next text comprehension and the same time, vocabulary size seems to be the aspect of language that is most influenced by levels of poverty and contributes to language and knowledge gaps of children enter school without the skills that are required.

Based on the descriptions above, the writer is interested to find out a way for enhancing students' memory related to vocabulary in preschool period. The previous research about preschool period, is want to investigate the influence of structured physical education on the psychomotor development of 3 to 5 year-old preschool children as Costa and friends stated (2015). The sample consisted of 324 students of both sexes ( 3 to 5 year-old) from 9 public kindergarten classes in Porto, Portugal. The result of this research is The role of the preschool education is fundamental for the child development process. At this stage, quality teaching practices should stimulate children, considering their individual characteristics and needs, to help them acquire during development several essential abilities and skills and can increase their overall development.

One way to enhancing preschool students' memory by retrieval practice. By retrieving the memory, it can reaccess the events or information from the past which have been encoded and stored in the brain. The use of retrieval practice as a learning strategy, by teachers and students, has been shown to increase students' long-term retention and transfer of knowledge to new situation (Agarwal, Bain, \& Chamberlain, 2012; Butler, 2010) in Agarwal and friends (2016).

Therefore, the writer use retrieval practice for improving students' memory in learning vocabulary in preschool period. The research question relates to the situations given is “Is retrieval practice effective enhancing students' memory in learning vocabulary of preschool period?"

\section{Retrieval Practice}

Most researches have employed some variant of the retrieval-practice paradigm as did by Anderson and friends project (1994) in Storm and friends (2015). participants first study a list of category-exemplar pairs (e.g., fruit-orange, metalsilver, fruit-banana, metal-copper), often consisting of several exemplars from 
several categories. Participants are then presented with category-plus-stem retrieval cues associated with half of the exemplars from half of the categories (e.g., fruitor__ $\quad$. Participants are instructed to use the cues to retrieve the appropriate exemplars from the earlier study list. Retrieval practice often consists of several rounds of trials, with participants retrieving the to-be-practiced exemplars multiple times. Finally, after a brief delay (usually 5-20 min), participants are tested on their ability to retrieve the items from the study phase. This retrieval-practice paradigm creates three types of items: Rpp items, Rp_ items, and Nrp items. Rpp items are exemplars generated during a Review of Retrieval-Induced Forgetting 143 retrieval practice (i.e., orange); Rp_ items are nonpracticed exemsplars from practiced categories (i.e., banana); and Nrp items are nonpracticed exemplars from nonpracticed categories (i.e., silver \& copper), as seen in figure 1.1 below:

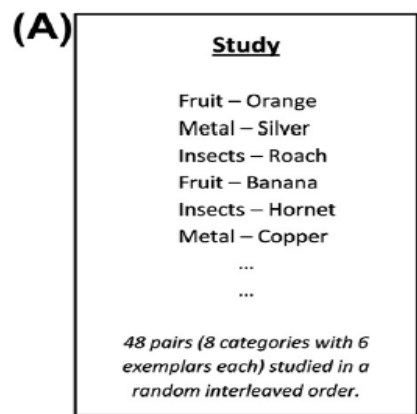

(B)

$$
\begin{aligned}
& \text { Rp+ items: Practiced exemplars from } \\
& \text { practiced categories } \\
& \text { Rp- items: Non-practiced exemplars } \\
& \text { from practiced categories } \\
& \text { Nrp items: Exemplars from non- } \\
& \text { practiced categories }
\end{aligned}
$$
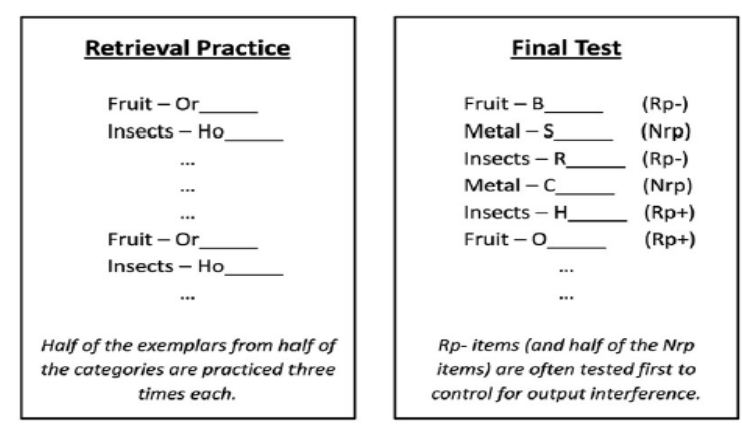

(C)

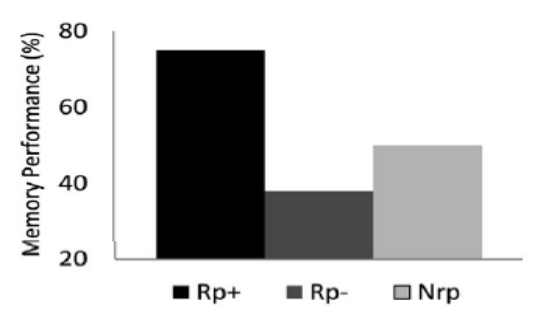

Figure 1. Retrieval-practice paradigm

The result showed Rpp items are recalled best, presumably owing to the benefits of testing that have been shown to enhance long-term memory (see Bjork, 1975; Roediger \& Karpicke, 2006). The more important finding, at least in the current context, is that Rp_ items are recalled less well than Nrp items. It is this diminished accessibility ofRp_ items relative toNrp items that is referred to as the empirical phenomenon of retrieval-induced forgetting 555678 et al., 1994).

Next, the research of Zee and friends (2018) using retrieval practice by watching educational videos in Massive Open Online Courses (MOOCs). However, merely watching a video is a relatively passive learning activity. To increase the educational benefits of online videos, students could benefit from more actively interacting with the to-be-learned material. Both interventions seemed to help students to perform better, but there was no apparent difference between the efficacy of these interventions. These studies show how the quality of online education can be improved by adapting course design to established approaches from the learning sciences.

If relates to assessments, Smith and Karpicke (2013) found that retrieval practice improves meaningful learning, and the most frequent way of implementing 
retrieval practice in classrooms is to have students answer questions. The result that they got is the challenge the simple conclusion that short-answer questions always produce the best learning, due to increased retrieval effort or difficulty, and demonstrate the importance of retrieval success for retrieval-based learning activities.

\section{Preschool Students}

English is one of international language which has been learned in many countries in the world. So that, English is taught started from the early age, specially in 3 to 5 year-old or pre school period. In Indonesia, there are kinds of preschool institution, such as playgroup, early-aged education (PAUD), pre- kindergarten, and kindergarden. Commonly, the intitutions have resemblant target in learning. Such as in kindergarten, the purpose is helping children achieve five developmental objectives, namely "Moral Development", "Cognitive and Language Development", "Physical Development", "Affective and Social Development", and "Aesthetic Development", with a view to nurturing children to attain all-round development in the domains of ethics, intellect, physique, social skills and aesthetics. One of the language input is vocabulary, including words.

Next, Hardley and friends (2015) did research to 4-5 years old students of kindergarten. The results suggest that ease of word learning may not be influenced solely by perceptual accessibility of words but also by the kind of instructional information that can be provided for different word types. This research took the pretest and postest to find out the children in defining words verbally and using gesture to express it. The test is about concrete words.

Based o the researches, one of input that is taught is vocabulary for preschool period. Basically, vocabulary knowledge can support student's comprehension, especially in reading skill to build the depth vocabulary. Commonly, student who is unable to utter words for the purpose of communication without understanding the speech, he could hardly be otherwise. He can't understand the meaning of words relates to objects, situation, and events. So that, one way to comprehend the language, it is important to observe what other say and how what is said first.

\section{Teaching Vocabulary}

Commonly, as the first input in language, children are taught in early age. One of the purpose is building their comprehension and their knowledge. Next, they can use the vocabulary itself in real communication by using skills. The writer taught the vocabulary by using media. The result is media can be used to improve the students' comprehension because they can find the vocabulary by their own activities. So that, they can build the vocabulary by fun learning.

\section{Method}

The data is collected by the data from PAUD Sakura Swadiri in 2017/2018 academic year in four times from 20 students. The ages started from 3 up to 5 years old. The data is analyzed by descriptive qualitative and quantitative data and oral test of vocabulary.

The procedures are: 
a. The writer conducted students' vocabulary test of colors, shapes, and numbers in English oraly

b. The researcher did presentation and explanation about the procedures of using busy book tso gain the students' memorization to PAUD teacher.

c. The teacher taught English using busy book to the students in three times.

d. The writer tested the students' vocabulary of colors, shapes, and numbers oraly.

e. The writer analyzed the data and confirm the data by oral test.

\section{Result And Discussion}

The writer analyzed the data taken into descriptions below:

Table 1. Students' Vocabulary Before and After Using Busy Book

\begin{tabular}{lllll}
\hline No. & Students & $\begin{array}{c}\text { Before Using Busy } \\
\text { Book }\end{array}$ & \multicolumn{1}{c}{$\begin{array}{c}\text { After Using Busy } \\
\text { Book }\end{array}$} & $\begin{array}{c}\text { The } \\
\text { Presentages }\end{array}$ \\
\hline 1. & L & 6 & 10 & $40 \%$ \\
\hline 2. & B & 12 & 15 & $20 \%$ \\
\hline 3. & $\mathrm{C}$ & 5 & 5 & 0 \\
\hline 4. & $\mathrm{D}$ & 7 & 12 & $41,6 \%$ \\
\hline 5. & $\mathrm{E}$ & 4 & 2 & $-10 \%$ \\
\hline 6. & $\mathrm{~F}$ & 8 & 10 & $20 \%$ \\
\hline 7. & $\mathrm{G}$ & 9 & 9 & 0 \\
\hline 8. & $\mathrm{H}$ & 6 & 10 & $40 \%$ \\
\hline 9. & $\mathrm{I}$ & 5 & 10 & $50 \%$ \\
\hline 10. & $\mathrm{~J}$ & 7 & 11 & $36,3 \%$ \\
\hline 11. & $\mathrm{~K}$ & 6 & 11 & $45,4 \%$ \\
\hline 12. & $\mathrm{~L}$ & 4 & 8 & $50 \%$ \\
\hline 13. & $\mathrm{M}$ & 3 & 6 & $50 \%$ \\
\hline 14. & $\mathrm{~N}$ & 5 & 9 & $44,4 \%$ \\
\hline 15. & $\mathrm{O}$ & 6 & 10 & $40 \%$ \\
\hline 16. & $\mathrm{P}$ & 6 & 11 & $45,4 \%$ \\
\hline 17. & $\mathrm{Q}$ & 9 & 12 & $25 \%$ \\
\hline 18. & $\mathrm{R}$ & 10 & 13 & $23,1 \%$ \\
\hline 19. & $\mathrm{~S}$ & 11 & 14 & $21 \%$ \\
\hline 20. & $\mathrm{~T}$ & 7 & 11 & $36,3 \%$ \\
\hline & Total & 136 words & 191 words \\
\hline
\end{tabular}

Based on the data taken, the writer find out the average of words that students have before and after using busy book as media is $71,2 \%$. Before using busy book, the writer asked students to mention the English words of numbers, colors, and shapes. Next, the writer noted each of students had. After applying busy book as media, most of students got more vocabulary than before. By checking one per one using oral test, the writer can indicate the words that they had. The most of the words which answered by students are more familiar with the students better than without using media. In this case, students didn't only memorize the words that they had known before, but also identify the adjective in concrete tools as seen in colors, shapes and also quantity as students should know in numbers. They can memorize the words directly and answer the answers easily by using busy book. 
This result is supported as Jones and friends (2015) that conducted experiments to find out which techniques that can be used in spelling instruction . The result shows retrieval practice at least as much as or more than rainbow writing as an effective method for spelling instruction. It indicates that retrieval practice is useful for training method for establishing testing effect to beginning spellers. More generally, in terms of educational practice, these results demonstrate the importance of empirical evidence for instructional techniques. When teachers seek to maximize the efficiency and effectiveness of classroom practices, they are often faced with a wide array of choices, sometimes with little more than their intuitions to guide them. Presumably, the use of rainbow writing has become popular precisely because it is believed to be more enjoyable for students. Our results indicate that is not the case. These findings serve as an important reminder that even when teaching methods have been developed to be fun and innovative, claims that they are educationally beneficial and that children find them appealing require (causal) empirical support.

\section{Conclusion}

Related to analyzing data, it can be summarized that retrieval practice is effective for enhancing students' memory in learning vocabulary of preschool period. In this case, retrieval practice improve students memories. By practicing, students can store the words longer and can build the comprehension of the vocabulary into related skills. In conducting retrieval practice, teacher asked to create the classroom to be unusual. Teacher can use many ways by creating new medias, applying some methods and techniques for improving students in learning activities. So that, retrieval practice is more fun and rigid for applying in the classroom. Besides, teacher notes the weaknesses of his students first, then, he can repeat the retrieval practice as long as students need in outside the classroom continued by parents or tutoring teacher.

Addition, retrieval practice as Trask and Bouton (2017) said that retrieval practice may not be sufficient to reduce the negative impact of a context change on instrumental behavior. A common elements explanation that supposes the physical and temporal contextual cues do not overlap may account for the findings more readily. Refers to operant conditioning theory, the results may be handled, however, by other theories that assume sampled contextual elements gain excitatory strength during acquisition panels compare mean responding during each session that preceded the retention interval with mean responding during the first 10 min of the session that followed the interval. Multiple contexts would increase the number of contextual elements that acquire excitatory strength, thereby increasing the chance that a novel context might contain shared elements that are already conditioned. However, it is not necessary to assume that elements corresponding to features of the physical context influence elements that might correspond to time. For example, some theories of timing have assumed the presence of a hypothetical cascading series of purely temporal stimuli that might be called temporal elements. Yet, another explanation might not invoke memory processes per set. In the operant situation, physical context change might disrupt the animal's ability to perform a response that was specifically adapted to the environment in which it was learned. An animal trained in multiple contexts might contrastingly develop a form of responding that is less disrupted by context change. However, the easy nose-poke response (snout placement within a divot in the wall) studied here would seem to be 
less vulnerable to such a performance process than a response, like lever pressing, which might depend on more subtle aspects of the animal's positionwith respect to the lever and leverage. A long tradition in animal learning theory has also argued that context change affects in animal learning tasks mirror those studied in human memory. However, in the present studies, this decontextualization of performance seemed limited to physical context changes during training. It is suggested that the result might imply that difficult retrievals are not sufficient to make an instrumental behavior context free.

Next, retrival practice effects the students in doing examination. As mentioned by Tran and friends (2014), many studies have found that review through testing produces better final recall than does review through restudying. This advantage, often dubbed the testing effect or the retrieval practice effect, has been studied for many years. However, the scope of testing benefits has not been fully charted. The testing effect thet benefits of retrieval practice have been found in a variety of memory tasks, including free recall of word lists (e.g., Tulving, 1967), pairedassociate learning (e.g., Carpenter, Pashler, \& Vul, 2006), foreign language vocabulary learning (e.g., Carrier \& Pashler, 1992), and learning content from prose passages (e.g., Roediger \& Karpicke, 2006). Testing effects have also been found in the classroom. For example, Carpenter, Pashler, and Cepeda (2009) showed that 8th grade students learning factual information (e.g., Who assassinated President Abraham Lincoln?) performed better for items on a memory test 9 months later when the review took the form of testing rather than restudy (see also McDaniel, Anderson, et al., 2007; McDaniel, Roediger, \& McDermott, 2007). Although the testing effect appears robust to changes in material and setting, the great majority of the testing effect studies have focused on explicit retrieval of the same information that was reviewed through testing.

The last, retrieval practice is used not only for students in classroom, but also help someone who gets impairement in language, as researched by Middleton and friends (2016) who found out the effects of retrieval practice and spacing effect to people who got aphasia. The purpose of the research was to examine how different types of learning experiences affect naming impairment in aphasia. Their methods is comparing the benefits of naming treatment that emphasized retrieval practice (practice retrieving target names from long-term memory) with errorless learning (repetition training, which preempts retrieval practice) according to different schedules of learning. The design was within subjects. Item s were administered for multiple training trials for retrieval practice or repetition in a spaced schedule (an item's trials were separated by multiple unrelated trials) or massed schedule ( 1 trial intervened between an item's trials). In the spaced condition, they studied 3 magnitudes of spacing to evaluate the impact of effortful retrieval during training on the ultimate benefits conferred by retrieval practice naming treatment. The primary outcome was performance on a retention test of naming after 1 day, with a follow-up test after 1 week. The results showed Group analyses revealed that retrieval practice outperformed errorless learning, and spaced learning outperformed massed learning at retention test and at follow-up. Increases in spacing in the retrieval practice condition yielded more robust learning of retrieved information. So that, we can conclude that retrieval practice can be a good way to treat someone who got impairment in aphasia. 


\section{References}

Agarwal, P. K., Finley, J. R., Rose, N. S., \& Roediger III, H. L. (2017). Benefits from retrieval practice are greater for students with lower working memory capacity. Memory, 25(6), 764-771.

Angello Storm, B. C, G., Buchli, D. R., Koppel, R. H., Little, J. L., \& Nestojko, J. F. (2015). A review of retrieval-induced forgetting in the contexts of learning, eyewitness memory, social cognition, autobiographical memory, and creative cognition. In Psychology of Learning and Motivation (Vol. 62, pp. 141-194). Academic Press.

Jones, A.C., Wardlow, L., Pan, S. C., Zepeda, C., Heyman, G. D., Dunlosky, J., \& Rickard, T. C. (2016). Beyond the rainbow: Retrieval practice leads to better spelling than does rainbow writing. Educational Psychology Review, 28(2), 385400.

Middleton, E. L., Schwartz, M. F., Rawson, K. A., Traut, H., \& Verkuilen, J. (2016). Towards a theory of learning for naming rehabilitation: retrieval practice and spacing effects. Journal of Speech, Language, and Hearing Research, 59(5), 1111-1122In Psychology of Learning and Motivation (Vol. 62, pp. 141-194). Academic Press.

Mufliharsi, R. (2017). Pemanfaatan Busy Book Pada Kosakata Anak Usia Dini Di Paud Swadaya Pkk. Jurnal Metamorfosa, 5(2).

Pollard-Durodola, S. D., Gonzalez, J. E., Saenz, L., Resendez, N., Kwok, O., Zhu, L., \& Davis, H. (2018). The Effects of Content-Enriched Shared Book Reading Versus Vocabulary-Only Discussions on the Vocabulary Outcomes of Preschool Dual Language Learners. Early Education and Development, 29(2), 245-265.

Smith, M. A., \& Karpicke, J. D. (2014). Retrieval practice with short-answer, multiplechoice, and hybrid tests. Memory, 22(7), 784-802.

Soenjono Dardjowidjoyo. Psikolinguistik, 2018, Jakarta, Penerbit, Arcan. Pg. 274

Steinberg, D. D. \& Sciarini, N. V. (2013). An introduction to psycholinguistics. Routledge.

Teixeira Costa, H. J, Abelairas-Gomez, C., Arufe-Giráldez, V., PAZOS-COUTO, J. O. S. É., \& Barcala-Furelos, R. (2015). Influence of a physical education plan on psychomotor development profiles of preschool children. Journal of Human Sport and Exercise, 10(1).

Tran, R., Rohrer, D., \& Pashler, H. (2015). Retrieval practice: the lack of transfer to deductive inferences. Psychonomic bulletin \& review, 22(1), 135-140.

Trask, S \& Bouton, M. E. (2017). Retrieval practice after multiple context changes, but not long retention intervals, reduces the impact of a final context change on instrumental behavior. Learning \& behavior, 1-9.

Van der Zee, T., Davis, D., Saab, N., Giesbers, B., Ginn, J., van der Sluis, F., ... \& Admiraal, W. (2018, March). Evaluating retrieval practice in a MOOC: how writing and reading summaries of videos affects student learning. In Proceedings of the 8th International Conference on Learning Analytics and Knowledge (pp. 216-225). ACM. 